

\title{
Family health narratives: midlife women's concepts of vulnerability to illness
}

Antje Lindenmeyer, Frances Griffiths, Eileen Green, Diane Thompson, Maria

Tsouroufli

\section{- To cite this version:}

Antje Lindenmeyer, Frances Griffiths, Eileen Green, Diane Thompson, Maria Tsouroufli. Family health narratives: midlife women's concepts of vulnerability to illness. Health, 2008, 12 (3), pp.275293. 10.1177/1363459308090049 . hal-00571447

\section{HAL Id: hal-00571447 \\ https://hal.science/hal-00571447}

Submitted on 1 Mar 2011

HAL is a multi-disciplinary open access archive for the deposit and dissemination of scientific research documents, whether they are published or not. The documents may come from teaching and research institutions in France or abroad, or from public or private research centers.
L'archive ouverte pluridisciplinaire HAL, est destinée au dépôt et à la diffusion de documents scientifiques de niveau recherche, publiés ou non, émanant des établissements d'enseignement et de recherche français ou étrangers, des laboratoires publics ou privés. 


\section{Family health narratives:} DOI: $10.1177 / 1363459308090049$

\section{midlife women's concepts of vulnerability to illness}

\section{Antje Lindenmeyer, Frances Griffiths, Eileen Green, Diane Thompson and Maria Tsouroufli \\ University of Warwick, University of Warwick, University of Teesside, University of Hertfordshire and University of Cardiff, UK}

A B S T R A C T Perceptions of vulnerability to illness are strongly influenced by the salience given to personal experience of illness in the family. This article proposes that this salience is created through autobiographical narrative, both as individual life story and collectively shaped family history. The article focuses on responses related to health in the family drawn from semistructured interviews with women in a qualitative study exploring midlife women's health. Uncertainty about the future was a major emergent theme. Most respondents were worried about a specified condition such as heart disease or breast cancer. Many women were uncertain about whether illness in the family was inherited. Some felt certain that illness in the family meant that they were more vulnerable to illness or that their relatives' ageing would be mirrored in their own inevitable decline, while a few expressed cautious optimism about the future. In order to elucidate these responses, we focused on narratives in which family members' appearance was discussed and compared to that of others in the family. The visualization of both kinship and the effects of illness led to strong similarities being seen as grounds for worry. This led to some women distancing themselves from the legacies of illness in their families. Women tended to look at the whole family as the context for their perceptions of vulnerability, developing complex patterns of resemblance or difference within their families.

KEYWORDS family history; life story; narrative; qualitative methodology; women's health

ADDRESS Antje Lindenmeyer, MA, PhD, Research Fellow, Health Sciences Research Institute, University of Warwick, Coventry CV4 7AL, UK. [Tel: +44 0247657 4654; fax: +44 0247652 8375; e-mail: Antje.Lindenmeyer@warwick.ac.uk]

Acknowledgements The British Sociological Association Code of Ethics was followed in all aspects of this research. Where individuals were accessed via an NHS organization, the research proposal was approved by the NHS Local Research Ethics Committee. 


\section{Family, risk and narrative}

Contemporary health care places great emphasis on identifying, responding to and modifying risk factors for disease, and there is a large body of literature on patients' or laypersons' understanding of risk (Parsons and Atkinson, 1993; Scott et al., 2005). However, an understanding of risk is different from a person's sense of vulnerability to illness expressed as a sense of 'am I going to get this illness in the future?' shaped by perceptions of individual strengths and weaknesses. There exists now a small but growing body of qualitative literature that explores the importance of personal experience of illness in the family for perceptions of vulnerability (Erblich et al., 2000; Rees et al., 2001; Walter and Emery, 2005). Two main issues are identified by these studies. First, perceptions of vulnerability are situated within a complex framework of kin relationships into which new information is integrated, such as when a relative is developing cancer. Second, abstract risk is personalized by looking for representativeness or salience, that is, a connection between the person and an affected relative. The connection may be identified as emotional closeness or similar traits (Walter et al., 2004). Recent research has addressed the way in which 'new genetics' interact with family stories (Davison, 1997; Finkler et al., 2003; Featherstone et al., 2006). Invisible genetic relations are given narrative meaning by looking for shared traits and mannerisms, which may then be seen as proof of inheritance and a sign of vulnerability to the same illnesses.

Narrative can be used as a mode of knowledge, making sense of the world, and as a tool for communication, constructed for the moment through interaction with others (Czarniawska, 2004). Narratives, concerning future health use knowledge of one's own body and family health patterns to understand possible futures, but also to communicate, as health stories confer a more general sense of who the narrator is and how she wants to be seen. Thus, health narratives are also autobiographical, linked to a sense of self, which can be changed or threatened by illness. Illness narratives are developed as a response to this biographical disruption, to give personal meaning to the illness (Bury, 1982; Asbring, 2001). Narratives can attempt a restitution of the self before illness, or offer the sufferer the chance to embark on a quest for a new sense of self (Frank, 1995). However, narratives are also performative, as by drawing on an existing repertoire of cultural resources, narrators strive to make their experience intelligible to themselves and others (Riessman, 1990; Bury, 2001). This is true for those with and without serious health conditions. Autobiographical stories about health are constantly created and re-shaped in the telling between family members, in consultations with health professionals and in the research interview. Moreover, kinship and family ties are continuously constructed and negotiated by storytelling about other family members (Mason, 2004). Autobiographical stories are 'designed with the others in mind ... maintaining a version of your life concordant with those of the others in the family' (Bruner, 2001: 34). Since women are traditionally assigned 
the role of kin-keepers (Richards, 1996), it predominantly falls to them to keep family health narratives alive, or alert family members to possible new dangers. For example, women were more likely to be aware of and therefore report a family history of heart disease (Hunt et al., 2000) and cancer (Richards, 1996).

This article will focus on how personal experience translates into a sense of vulnerability. It is our contention that salience is created through narrative, both individual life story and collectively shaped family history. Both types of narrative provide a sense of continuity in an uncertain world. For midlife women (aged 45-64 for the purposes of this study), established roles dissolve and new identities need to be forged as children leave the home and women may retire from work. For these women, older relatives, especially parents, provide clues to what the future may hold. The narrative approach to health employed by the women interviewed in this study can be seen as part of a process of making sense of embodied experience in the light of a fundamental uncertainty about what might happen to the body in the future. An understanding of this process is needed for any dialogue with this personalized sense of vulnerability rather than merely identifying it as a target for health education. While many studies of risk perception look at one condition only, the interviews that inform this article address concerns about present and future health in general, and midlife women's health in particular. Thus, they offer a window into the complexity of family history as a whole, and how the experience of illness in the family is inextricably bound up with family relationships.

\section{Methods}

This article reports secondary qualitative analysis of semi-structured interviews originally conducted in the UK for the ESRC-funded project Innovative health technologies at women's midlife: Theory and diversity among women and 'experts' (Griffiths et al., 2003). ${ }^{1}$ The relevant health technologies were HRT, and screening with mammography or bone densitometry. The project included interviews with women, audio recording of health care consultations and interviews with health professionals. For the interviews with women, the sampling strategy was to recruit for diversity across a number of different dimensions. Women were recruited for diversity of use of HRT or screening from health care sites (HRT clinic; bone clinic; mammography screening and follow-up breast assessment clinic; general practice). Women from relevant community organizations were recruited for diversity of ethnicity, sexual orientation and disability. Demographics were obtained by asking respondents to fill in a brief questionnaire (see Table 1). The sample included women with a wide range of formal educational achievement. The number with higher degrees was enhanced by recruiting for the pilot interviews in a university. However, these interviews are included as they contain rich narrative data. 
health: 12(3)

Table 1 Demographics of participamts

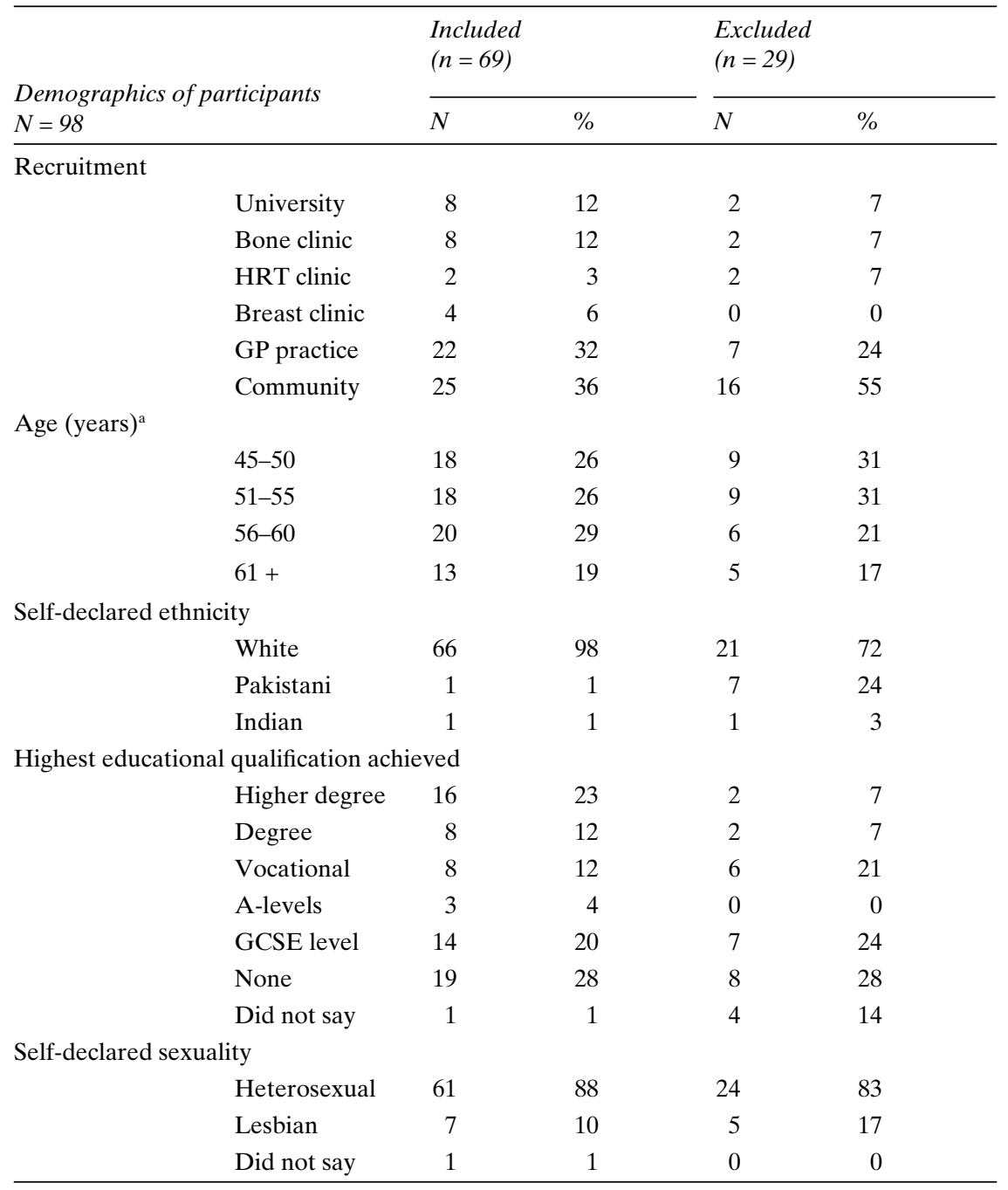

a The study aimed at interviewing women 45-64 years of age, but two women were found to be older (67 and 68) when demographics were obtained.

During the semi-structured interview with a woman researcher, women were asked about their health concerns in general, their views regarding HRT, mammography and bone densitometry and their experiences of interacting with health professionals. The interviews were originally aimed at obtaining data on women's opinions and experiences regarding these health interventions and were not explicitly aimed at exploring family history. However, women often responded to questions about present and future health concerns by talking about close family members. This prompted our secondary analysis of this set of responses. Of 98 women that 
were interviewed, 61 mentioned their mothers' health, often together with that of other close relatives, while another eight did not talk about mothers but mentioned fathers, siblings, or both, giving a total of 69 women in this analysis. Of the 29 participants who did not mention family members and were therefore excluded from this analysis, seven were Pakistani women interviewed through an interpreter, a situation that may not be conducive to storytelling. On other socio-economic dimensions, there were no major differences between those included or excluded from this analysis, except there were more graduates among the women included (see Table 1).

The interviews were entered into N-Vivo software for ease of data retrieval, and any mention of health in relation to family members was coded. To provide an overview of women's health concerns related to illnesses suffered by family members, our analysis begins with a summary of responses from 60 women that set their own health in relation to that of others in the family. Nine women talked about health in the family in more general terms. In 47 of the 60 interviews the women talked about family health in the first part of the interview when asked about general health issues including present and future health concerns. In the other 13 interviews, women talked about family health in relation to questions on HRT and screening, or on talking to health professionals. How women talked about family health was categorized and is described below. Those shifting between categories were categorized as being ambivalent. We explored whether the way concerns were expressed about different conditions depended on type of condition. We also looked for disconfirming cases, where concerns were expressed about conditions that no family member suffered. Results from this first stage analysis set the scene for an in-depth analysis of narrative representations of health in the family, which will draw on theories of the narrative construction of kinship from sociology and medical anthropology. These theories will drive the analysis of the interview data where women compare themselves to other family members.

\section{Worrying about the future}

Health promotional adverts and the media urge us to be aware of ever more risk factors for future disease (Ruston and Clayton, 2002). Critics of a preventive medicine based on risk factors have argued that this focus on risk may lead to 'surveillance medicine', with the body permanently at risk, needing monitoring and intervention (Armstrong, 1995). Women's awareness of their vulnerability to illness is heightened by nationalized screening programmes for breast or cervical cancer, which may lead to women feeling personally responsible for averting illness through control of the body (Lupton, 1995). This culture of risk forms the background for the concerns expressed by women in this study. Many women worried about their vulnerability to future illness. While most expressed a worry about specific conditions, some were uncertain or ambivalent about genetic links, and some felt a certainty of increased risk or inevitable decline. Only 
a few women were optimistic about the future as their family enjoyed good health. ${ }^{2}$

\section{Worry about a specific condition}

Of the 69 women included in this analysis, 23 were concerned about one or more specific conditions suffered by relatives. Conditions mentioned were breast cancer (seven women), other cancers (five), heart disease (five), arthritis (two), asthma (one), diabetes (one) and stroke (one). ${ }^{3}$ For some, this was a slight anxiety; others described it as 'quite worrying really' (Woman04); or 'quite daunting' (Woman07). For some, a family history of illness was a source of real fear: 'the only thing I have a fear of and you're probably not going to ask me and it probably might never happen. My parents died of heart disease' (Woman55, aged 53, catering assistant).

Other women strongly felt that they would follow in family members' footsteps. One woman worried about a family history of alcoholism and heart disease:

my mum died at $54 \ldots$ of a heart attack ... on her side ... everyone's died young. A lot of that's been drink-related. ... Personally I, I think I'm going to go of heart rather than cancer. But that's what I feel in my bones, but ... whether that's true or not, I don't know. (Woman29, aged 48, charity manager)

Another woman thought that she was at an increased risk of breast cancer:

my grandmother, my, my mother, my sister, my grandmother and my auntie all died of breast cancer ... and I feel that there is, there is a umm a hereditary thing there, somewhere ... along the line, whether it skips generations I wouldn't know but I feel that there's something. (Woman67, aged 60, retired)

Women in this category were uncertain whether they would suffer from the same illnesses as their relatives, but worried because of their personal experience of illness in the family or because they thought there was a genetic link. A combination of personal experience and heightened awareness of family risk has led to Woman29 (see earlier) having a strong though quickly disavowed - emotional certainty that she would suffer the same disease in the future.

\section{Uncertainty about genetic links}

This category consists of 15 women who expressed uncertainty or moved between categories during the interview. In these interviews, concern was expressed about the following conditions: arthritis (four women), osteoporosis (three) and dementia (three), cancer (two), endometriosis (one), asthma (one) and post-natal depression (one). Personal experience of arthritis, osteoporosis and dementia in family members left a strong impression on the women, as they were seen as leading to a loss of mobility and independence.

Ten women in this category raised inheritance as a possibility, but were unsure about their own knowledge, or that of medicine in general. Some had heard, or read, that illnesses like osteoporosis or dementia could 
be inherited. Heredity was also mentioned as a possible explanation for the same illness (e.g. arthritis) happening to several members of the family. Ambivalence often related to uncertainty about genetic inheritance. Four women pointed out the contradicting picture presented by two sides of the family. One side of the family was seen as prone to illness, the other to good health: 'the thought of I might lose my mind like I'm seeing with my mother now is quite worrying really but I'm just sort of thinking if I take after my father I'll be all right you know (laugh)' (Woman04, aged 58, retired teacher).

For three women, the presence of different conditions in the family created dilemmas deciding whether to take HRT, as they had family members with breast cancer and osteoporosis. ${ }^{4}$ As one woman put it:

So you know it seems like not a very good choice, it's almost like you're choosing which disease you are going to (laugh) have more chances of getting. You can limit the chance of one but you then increase the chance of another. (Woman51, aged 48 , lecturer)

\section{Certainty about increased risk or inevitable decline}

Certainty that illness or decline in the future was highly likely or inevitable was expressed by 16 women. Six women said that the increased risk of the condition because of family history (in four cases for osteoporosis, one for breast cancer and one for high cholesterol) had been mentioned to them by a health professional and/or shown up by a test. This was usually mentioned as a response to questions about screening, or interactions with health professionals. For one woman, a recent bone densitometry result was seen as so crucial to health that the woman brought it up at the beginning of the interview. These test results were perceived by the women as confirming the influence of family history. This is especially apparent in one woman, whose consultation in the bone clinic was audiotaped for this project. In the consultation, the doctor stated that her bone density has started to fall, though her bones were still 'alright' (Consultation 001). The doctor also mentioned her mother having osteoporosis. In the interview, the woman interpreted her test result in the context of family history and assumed that she already had osteoporosis: 'they [doctors] were frightened it [osteoporosis] would run in the family which unfortunately it has' (Woman60, aged 58, housewife). In this case, linking the test result to family history increased the blurring together of current and future risk (Green et al., 2006).

Five women expressly felt sure that a condition (heart disease, osteoporosis, breast cancer, diabetes) 'ran in the family' without mentioning having this raised by a health professional. Six women saw the ageing of their parents as prefiguring their own inevitable decline, with decreasing mobility or dementia a certainty 'unless a number nine bus comes along and I'm not looking the right way' (Woman07, aged 55, housewife). Again, awareness about family risk, in some cases heightened by health professionals' statements, and first-hand experience of illness in the family contributed to the women's feeling of increasing vulnerability. 
health: 12(3)

\section{Optimism about the future}

In this category, six women were optimistic about their future health, talking about their family history of good health, with none in the family with conditions like heart disease, or having relatives that lived to a healthy old age. For example, one woman felt that as her grandmother died at 101, she had 'a few more years left' (Woman02, aged 60, community advocate). However, there was also a sense that one should not feel too secure: 'So I mean it [menopause] didn't affect my mum ... I'm expecting just you know it's nothing, slide through. So I'm probably in for a big fall' (Woman49, aged 48 , lecturer).

A possible explanation for the hedging statements that often followed expressions of certainty that illness was not in the family may be a reluctance to appear hubristic and therefore attract trouble, reflecting an understanding of health in terms of fate or luck (Davison et al., 1989, 1992).

\section{Disconfirming cases}

Only four women expressed concern about illness that was not 'in the family', but relevant to them for other reasons. These women also mentioned concern with illness suffered by relatives and are included in the categorization above. One woman, drawing on her professional knowledge as a nurse, stated:

I know that at my age we are more susceptible to breast cancer. Luckily for me, it's not in my family, no hereditary of breast cancer, so although it could still happen, I know that I haven't got that to worry about too much, but I do still check myself. (Woman94, aged 47)

Similarly, another woman had gone back to her GP to discuss discontinuing HRT 'because of the breast - not that I've got any breast cancer history in my family, you've got to be so careful, that it could cause breast cancer' (Woman34, aged 57, medical receptionist). One woman worried about arthritis and heart disease that were present in her family, but also about breast cancer 'not because it's in my family just because ... it affects such a large percentage of the population' (Woman51, aged 48, lecturer). A social worker was concerned about breast cancer as 'a few years ago, there seemed to be just so many women who uh, had breast cancer.' (Woman26, aged 55). It is striking that only these four women said that they worried about breast cancer not because of family history, but because of its high prevalence in the population of women over 50 (reflected in the social worker's contemporaries). This is indicative of the strong role that experience of illness in the family plays in shaping perceptions of vulnerability in these women.

\section{Summary}

The women talking about health in their families mentioned a wide range of conditions and concerns. However, the overarching theme is one of uncertainty about the future. Women worried about illness that could be deadly 
(heart disease, cancer), but also about conditions they saw as leading to loss of independence such as arthritis and dementia, or looked for patterns of illness in their families that might be due to inheritance. Some women attempted to keep worries at bay by disavowing an emotional certainty that they would get cancer or heart disease in the future. Worries about future health were often accompanied by stories in which respondents set themselves in relation to other family members. In order to understand why individual women saw themselves as vulnerable to illness, we turn to an analysis of these stories, focusing especially on narratives in which family members' appearance was discussed and compared to that of others in the family.

\section{Resemblance and kinship}

In narratives about family history, resemblance and kinship are closely linked. This link is perpetuated in 'family lore' about inheritance, with linked systems of physical traits, personality traits and susceptibilities to illness. If a person exhibits one trait or contracts one illness, family members may expect the linked illnesses to emerge (Davison, 1996). Qualitative studies on family discussions about inheritance (Becker et al., 2005; Featherstone et al., 2006) have focused on the connections between narrative and the visual. Visual depictions and non-visual representations of illness and family 'traits' (defined for the purposes of this article as characteristics that family members consider to be inherited, e.g. body shape, facial features, mannerisms or aspects of personality) are constantly being created, reinforced and honed in well-worn family stories.

Featherstone et al.'s study of family interactions around inherited conditions found that, in families where a genetic condition has been diagnosed, family members watch each other for signs of illness and resemblance to family members that are already ill. 'Surveillance is a tool used to piece together the past and present in order to visualise the future' (Featherstone et al., 2006: 75). Responses in this study suggest that this finding can also be generalized to families without a genetic condition. Several women in this study compared themselves to other relatives, or their father's or mother's side of the family. Some visualized their possible future selves by looking for signs of turning into (or 'becoming like') their ageing relatives. We analyse in depth some of the complex narratives about health in the family in our data set. These narratives are informed both by visual representation of illness (such as descriptions of a stooped appearance or a change in walking) and looking for resemblance to other family members. Our analysis contributes to an explanation as to why and how illness in the family translates into a sense of an illness becoming relevant to the woman herself which has been defined as 'salience' (Walter et al., 2004). 
Narrative and visual elements are interlinked in 'resemblance talk', everyday chit-chat about family likeness that forges connections or marks rifts between family members (Becker et al., 2005). Recent studies on lay perceptions of genetic inheritance have picked up on the tendency to assume that similar appearance to family members implies a shared risk of contracting illness. Respondents in these studies looked for patterns of repetition in their families. However, this was made more complex by distinguishing between male and female relatives, mothers' and fathers' side, and the perception that some illnesses 'skip a generation' (Davison, 1996, 1997; Richards, 1997; Rees et al., 2001; Scott et al., 2005). However, respondents in Emslie et al.'s (2003) study were aware that people might want to see family resemblances, and that family members disagreed about who resembled whom. From these studies, it emerges that narratives about medical family histories are shaped by many family members, taking into account several generations. However, as collective histories, they are also always subject to change and disagreement.

\section{Perceptions of likeness}

Of the women in our study who were not explicitly asked about inheritance, only one woman, whose grandmother, mother, sister and aunt all died of breast cancer, forcefully connected visual appearance to illness 'candidacy' (Davison et al., 1992):

I do have a niece ... who was my sister's daughter ... I, I keep saying to her, in fact she had such big breasts, she's had a breast reduction, and she was huge ... but I, I keep saying to her you know you, you- ... I feel she's a prime candidate for breast cancer. (Woman67, aged 60, retired)

Stories about 'being like' family members included concerns about ageing: 'my grandfather suffered very badly with severe bronchitis, and I feel as I'm getting older, I'm getting more like him' (Woman34, aged 57, medical receptionist). Another woman saw a similarity between herself and her mother - they were both oldest daughters - in terms of having similar risk of osteoporosis.

Women used the context of the whole family to look for meaningful patterns of health and illness. Many found contradictory patterns that needed explaining, for example one parent and siblings suffering from arthritis while the woman herself did not. Some women described different 'sides' of the family, with distinctly different vulnerabilities. Others developed complex family patterns not reducible to 'sides'. In this context, perceptions of vulnerability could be based on likeness, as for this woman who worried that she might develop severe arthritis like her paternal aunt, as she was not 'like' her mother's side of the family:

I have an auntie who's crippled, absolutely crippled with arthritis and it worries me that I've inherited that side of the family rather than my mother's side that's from my father's side of the family ... But I'm not particularly like her, 
my mum's side of the family, I'm more like my father's side of the family so whether I'll be like that I don't know. (Woman51, aged 48, lecturer)

This woman's narrative develops a relational sense of self as her father's daughter, more 'like' (without specifying how exactly) her father's side of the family and therefore perhaps more likely to have inherited her aunt's arthritis. In another interview a mother and daughter of Pakistani origin, both present at the interview, developed a family tree, with 'Nanna' (mother's mother), overweight, asthmatic and with cardiovascular problems who closely resembled the mother's 11-years-younger sister: 'she's very, very big ... she's got asthma, she's very similar, she's a Nanna'. They also saw resemblance between 'Nanna' and another daughter not present at the interview 'my daughter ... she's has got so many things, she's not in good health'. The mother herself has no weight problems and is a 'role model' as she is so fit and healthy, according to the daughter. However, the mother is still worried about getting asthma: 'if I have got little bit [of a cough] then I'm worrying maybe I got asthma because my mother was like that and she died only 55' (Woman78, aged 68, full-time carer). The exchange between mother and daughter in the interview provides a glimpse of family members shaping their family history. This was the only interview in the set of data analysed where another family member was present as the study aimed to interview women individually. Our analysis of the collective shaping of family history is therefore based on women's individual accounts.

The emphasis on 'likeness' had two consequences. First, being 'like' family members was connected to vulnerability to the same illnesses. Stating the emotional certainty that they 'felt' they would get the same illness in the future, women in this study referred to strong relational ties between family members. Second, women looked for a link between relatives to explain the occurrence of similar patterns, although they were unsure whether this link was genetic. This could explain why these women especially looked at conditions where there might be visible consequences, such as osteoporosis (shrinking) and arthritis (swollen joints, difficulty walking). The medical anthropologist Kaja Finkler argues that a preoccupation with genetics leads to a 'medicalization of kinship', which paradoxically induces both closer kinship ties and increased anxiety surrounding these kinship ties (Finkler et al., 2003). In our study, the women's stories employed what could be called a medicalization of resemblance. For many women who remarked on a likeness between family members, likeness was a reason for worrying about contracting a similar condition. The women's narratives based on family stories about health develop an image of a self permanently at risk.

\section{Perceptions of being 'unlike'}

A way of escaping the feeling of being at risk is to refuse recognition of likeness and see oneself as unlike the affected relative. In the following, we will focus on participants' expressions of being 'unlike' family members. 
Lawler (2000) conducted a qualitative study interviewing both mothers and daughters, and found that inherited traits shared between family members were constitutive of the self. We all 'inhabit a social world in which the self can be explained in terms of inherited characteristics' (Lawler, 2000: 58). However, since stories about inheritance assume that children are a combination of many relatives' traits, they enable daughters to distance themselves from the mothers: 'certain characteristics must be recognized as being shared with forebears to enable the self to be understood in this way' (Lawler, 2000: 59, emphasis added). Recognizing or not recognizing shared traits can be enacted, by identifying oneself or others with the 'father's side' rather than the 'mother's side' of the family, or vice versa. For women, this might break the pattern of girls said to 'take after' their mothers (Emslie et al., 2003).

These narrative patterns enabled women in our study to distance themselves from family members - especially those with medical conditions - by recognizing the difference between them. This occurred especially between siblings. One woman distanced herself from her siblings who suffered from various health problems, arguing that they all had high blood pressure, whereas her own blood pressure was low. Several women compared their menopausal symptoms with their sisters' and from their difference concluded that they were lucky. Distancing statements, both for parents and siblings, could refer to their own better self-care, especially eating a better diet. Other women saw differences between generations, with health interventions more available to younger generations because of younger women's greater assertiveness, progress in medicine and better access to health care.

However, dissimilarity could also lead a woman to seeing herself as worse off. One woman described her sister as 'always the lucky one' (Woman90, aged 59, retired), and therefore sailing through the menopause. Another woman saw great differences between her own and her sister's vulnerability to illness based on her own post-Second World War time of birth, with her later-born sister being much more resilient. The most striking pattern in this area, however, was a feeling of 'role reversal' between the woman and her mother. One woman who found walking very painful and could walk only short distances stated:

Yeah because I always thought because my mother was a very active person for all she was a bad walker but it never ever stopped her ... and I think well I can't do that ... it's so funny when you think back I always thought I'd be doing what my mum was doing. ... But you can't. (Woman65, aged 59, on incapacity benefit)

Another woman, in a wheelchair because of MS, explained:

I mean I feel that I've aged 20 years beyond my time because I have a mother who's 82 , and really she is as I should be. And I am as I would expect her to be. I've recently been able to go swimming because of the personal assistant, but my mother swims three times a week. And my mother's doing the washing up, 
my mother's doing the cooking. I can't do any of those. So I feel I've aged because of my illness. (Woman71, aged 58, retired)

Two other women, one with arthritis and the other with a more general loss of energy, also were disappointed that they were unexpectedly 'slowing down', while their mothers had been, or continued to be, active. In these statements, we can see a negative effect of comparison. Because the women had assumed to be like their mothers were, not being as fit and healthy caused a sense of betrayal and premature ageing.

While claiming resemblance and therefore close family ties could lead to a woman feeling more at risk, choosing not to recognize resemblance or putting the stress on non-resemblance enabled women to distance themselves from illnesses suffered by other family members. However, for other women, perceiving themselves as unlike their mothers was unavoidable as it was a lived reality that they were unable to do what their mothers had done. As with recognition of likeness, recognition of un-likeness can be double-edged. It enabled some women to distance themselves from relatives suffering from health conditions, but for others it led to self-identification as the 'unlucky' daughter or sibling whose infirmity was measured against other family members' good health.

\section{'Becoming like': looking to the future}

A related device of family lore is looking to members of the family in order to predict one's own future. A determinist view of genetics can collapse past and future into one another, with the future condemned eternally to repeat the past: 'the ideology of genetic inheritance encapsulated in one's DNA crystallizes the past and the future into the present lived experience of the now, compressing time into an everlasting present fraught with fear of falling ill in the future' (Finkler, 2005: 1066). This might have happened to the five women who, as described as part of the 'certainty of risk' category, worried that disease was now 'in the family', doomed to repeat itself:

Some families unfortunately seem to have cancer in the family and others seem to have heart and our family seems to be heart problems, so that's what concerns me in the future. (Woman17, aged 51, tax advisor)

I find now, in the family, suddenly, in their 80s and 90s, relations have got it. We didn't have cancer in the family, now suddenly I'm thinking, oh, it's started, so therefore - you know, is there a risk? (Woman44, aged 63, retired)

The five women whose increased risk was raised or confirmed by a health professional may have interpreted their concern as a confirmation of this belief (Davison, 1997). One woman who had a biopsy 'right away' because her sister had had breast cancer argued that any family history of a serious condition should be known to health professionals: 'And I think if there is anything at all in families they should be known, they [doctors] should be told and that you do want reassurance' (Woman77, aged 54, retired). 
The previous section focused on women comparing themselves to other family members and claiming to be like, or unlike them. Here, we focus on how women look at a family history of illness, and worry that it also may be in their future. Several women visualized the connection between past and future and saw themselves as 'becoming like' their older relatives. Members of families with a genetic condition 'look to past and current generations for signs of the ... disease, they see their future in those who have gone before' (Featherstone et al., 2006: 98). For participants in this study, the visual image of the ageing parent was powerful. 'I look at my parents ... I draw from them what I'll - may be like, which is the only yardstick I have' (Woman48, aged 50, administrator).

Osteoporosis was described in vivid visual images, with relatives 'shrunk', 'crippled', 'bent', 'hunched over', 'crumbled' from osteoporosis. These visual images represent fracture as a loss of self, with the sufferer becoming almost unrecognizable as a person. They evoke a frail body with bones that break easily and the appearance of an old, stooped lady (Reventlow et al., 2006). Women's fear of developing osteoporosis was one especially potent instance of a more general tendency for women to picture themselves in their mother's position: 'I look at my mother and I think ...'; 'look at my mother ...' were common responses to questions about future health, and a few specifically 'saw themselves' with osteoporosis, arthritis or Alzheimer's like their mothers:

Yes, I can see, I sort of envisage myself with osteoporosis and umm, I do see myself, sort of maybe being sort of arthritic, which probably sounds bizarre, but sort of whether I'd suffer with Alzheimer's. (Woman48, aged 50, administrator)

I've heard that senile dementia is, can be hereditary. And that does worry me when I see my mother - her [memory] time span was five minutes. (Woman15, aged 55 , quality controller)

I look at my mother and think I may go, be like her. She's shrunk which is something that concerns me because I am only 5 foot one and a bit. (Woman56, aged 48 , lecturer)

I watched my mother suffering with osteoporosis and basically died of it because of fractures, followed by strokes and heart attacks, so - so yes, I'm very aware of watching the osteoporosis. (Woman64, aged 64, retired)

'Seeing' what happened to parents translates into worries about becoming like them. For Woman64 quoted above, 'watching' has a twofold meaning: watching her mother's suffering, but watching for signs of the condition. Women visualized other illnesses their mothers suffered, including heart failure 'like living on a time bomb' and colon cancer 'end up with a colostomy bag'. One woman perceived herself as already 'turned into' her aged relatives:

my father's two sisters who were my aunts and I was very fond of them, they were, were really big women ... And when I was young, I mean, as a child I used 
to look at them and say 'I am never going to look like that' ... and now I can look in the mirror and think I'm looking at one of them. (Woman30, aged 61, retired)

Many women were aware of diseases with a highly publicized genetic aspect like cancer, or heart disease. Resemblance to the affected relative could play a role in increasing the worry. If a woman expressed fear of becoming like a relative, this almost always entailed some kind of loss of self, either through a perceived loss of mobility or changed appearance (arthritis, osteoporosis) or loss of memory (stroke, dementia). Woman30 quoted above describes feeling a loss of her sense of self by becoming 'one of them'. This fear could be exacerbated by the responsibility of caring for a relative. For one woman, the experience of seeing her mother deteriorate led to the following forceful statement:

I would hate to have a stroke and be like - 'cause my Mam did that. And I nursed her for two and a half years. And I would hate to go like that. I would like euthanasia. You know. Put me to sleep. (Woman90, aged 59, retired)

Personal experience of the way parents aged or coped with illness were highly influential in women's expectations of their own future health. This was also the case for many women who had not explicitly stated this in visual terms. While women whose mothers were fit and healthy were cautiously optimistic about the future, coping with illness was also a source of optimism for the daughters. Several stressed how their mothers did not let their health conditions stop them from being active and mobile. One woman said that seeing her mother being open about her breast cancer and coping well made her less fearful about the possibility of breast cancer in the future; while another, a wheelchair user, saw lucidity as most important: 'My mom ... her grey matter was fantastic right until literally she died. Her arthritis let her down, but umm yeah as long as I can still read and hold a conversation ... I think I'll be all right?' (Woman68, aged 63, administrator). This perspective led to a more optimistic look into the future. Family history might be doomed to repeating itself, but the individual could cope with it and achieve a good quality of life.

Visualized narratives provided a link between women's own sense of self, their experience of their mothers ageing and their hopes and fears for the future. While remembering how their mothers coped well with illness engendered a sense of cautious optimism, a relative's perceived loss of self through dementia or inability to walk created very strong anxieties, as women imagined themselves in a similar condition. Narratives about health created a relational sense of self connected to parents and other family members, which led to women perceiving themselves as more vulnerable to illness. 


\section{Conclusion}

Storytelling about family health is instrumental to women's own sense of vulnerability. Many women feel very uncertain about future health and worry about health conditions that relatives suffered. Stories about family health and women's own experiences are used to develop a sense of personal vulnerability and imagine possible futures. In telling stories about how they see themselves at present and how they might be like in the future, the women in this study drew on a narrative visualization of both illness and family relationships. This led to a 'medicalization of resemblance' with similarity both a source of comfort and of worry. Some women were able to refuse to recognize similarity and distance themselves from the legacies of illness in their families by stressing they are unlike affected relatives, while others felt betrayed as they were unable to lead the same active lives as their mothers. Others again drew strength from witnessing how relatives coped with disabling illness.

Narrative models of vulnerability can be very complex. They are deeply bound up with a sense of self, perceived as related to a continuous family history. As the self is subject to constant change as the body ages, looking at mothers and other older relatives may provide clues to the future self. Understanding the complexity and experiential nature of these narratives of health in the family is important for health professionals engaging in conversations with patients about family history.

\section{Notes}

1. All data from the study are available for bona fide use via the Economic and

Social Data Service Qualidata: http://www.esds.ac.uk/qualidata/ (accessed 19 June 2006). Participant codes in this article follow those submitted to the archive.

2. Nine women were not accounted for by these categories, as they did not mention concerns for future health related to health in the family; for example, they already had MS or diabetes, or they compared their own experience of the menopause with their sisters'.

3. The named conditions are in the interviewees' own words.

4. The interviews were held in 2001-3. Until 2002, HRT was widely used as a treatment to prevent osteoporosis although there was concern that it increased risk of breast cancer. In 2002 two major studies (the Million Women Study in the UK and the Women's Health Initiative trial in the USA) confirmed the increased risk of breast cancer. HRT is now less often used to prevent osteoporosis.

\section{References}

Armstrong, D. (1995). The rise of surveillance medicine. Sociology of Health and Illness, 17(3), 393-404.

Asbring, P. (2001). Chronic illness - a disruption in life: Identity-transformation among women with chronic fatigue syndrome and fibromyalgia. Journal of Advanced Nursing, 34(3), 312-19. 
Becker, G., Butler, A. and Nachtigall, R.D. (2005). Resemblance talk: A challenge for parents whose children were conceived with donor gametes in the US. Social Science and Medicine, 61(6), 1300-9.

Bruner, J. (2001). Self-making and world-making. In J. Brockmeier and D. Carbaugh (Eds.), Narrative and identity: Studies in autobiography, self and culture, pp. 25-38. Amsterdam: John Benjamins.

Bury, M. (1982). Chronic illness as biographical disruption. Sociology of Health \& Illness, 4(2), 169-82.

Bury, M. (2001). Illness narratives: Fact or fiction? Sociology of Health \& Illness, 23(3), 263-85.

Czarniawska, B. (2004). Narratives in social science research. London: SAGE.

Davison, C. (1996). Predictive genetics: The cultural implications of supplying probable futures. In T. Marteau and M. Richards (Eds.), The troubled helix: Social and psychological implications of the new human genetics, pp. 317-30. Cambridge: Cambridge University Press.

Davison, C. (1997). Everyday ideas of inheritance and health in Britain: Implications for predictive genetic testing. In A. Clarke and E. Parsons (Eds.), Culture, kinship and genes: Towards cross-cultural genetics, pp. 167-94. Basingstoke: Macmillan.

Davison, C., Frankel, S. and Smith, G.D. (1989). Inheriting heart trouble: The relevance of common-sense ideas to preventive measures. Health Education Research, 4(3), 329-40.

Davison, C., Frankel, S. and Smith, G.D. (1992). The limits of lifestyle: Re-assessing 'fatalism' in the popular culture of illness prevention. Social Science and Medicine, 34(6), 675-85.

Emslie, C., Hunt, K. and Watt, G. (2003). A chip off the old block? Lay understandings of inheritance among men and women in mid-life. Public Understanding of Science, 12(1), 47-65.

Erblich, J., Bovbjerg, D.H. and Valdimarsdottir, H.B. (2000). Looking forward and back: Distress among women at familial risk for breast cancer. Annals of Behavioral Medicine, 22(1), 53-9.

Featherstone, K., Atkinson, P., Bharadway, A. and Clarke, A. (2006). Risky relations: Family and kinship in the era of new genetics. Oxford: Berg.

Finkler, K. (2005). Family, kinship, memory and temporality in the age of the new genetics. Social Science and Medicine, 61(5), 1059-71.

Finkler, K., Skrzynia, C. and Evans, J.P. (2003). The new genetics and its consequences for family, kinship, medicine and medical genetics. Social Science and Medicine, 57(3), 403-12.

Frank, A.W. (1995). The wounded storyteller: Body, illness, and ethics. Chicago, IL: University of Chicago Press.

Green, E., Griffiths, F. and Thompson, D. (2006). 'Are my bones normal, Doctor?': The role of technology in understanding and communicating health risks for midlife women. Sociological Research Online, 4: www.socresonline.org.uk

Griffiths, F., Green, E., Backett-Milburn, K., Bendelow, G., Thompson, D. and Tsouroufli, M. (2003). Innovative health technologies at women's midlife: Theory and diversity among women and 'experts': End of award report (L218252038). Available at http://www.esrcsocietytoday.ac.uk/esrcinfocentre

Hunt, K., Davison, C., Emslie, C. and Ford, G. (2000). Are perceptions of a family history of heart disease related to health-related attitudes and behaviour? Health Education Research, 15(2), 131-43. 
Lawler, S. (2000). Mothering the self: Mothers, daughters, subjects. London: Routledge.

Lupton, D. (1995). The imperative of health: Public health and the regulated body. London: SAGE.

Mason, J. (2004). Personal narratives, relational selves: Residential histories in the living and telling. Sociological Review, 52(6), 162-79.

Parsons, E. and Atkinson, P. (1993). Genetic risk and reproduction. Sociological Review, 41(4), 679-706.

Rees, G., Fry, A. and Cull, A. (2001). A family history of breast cancer: Women's experiences from a theoretical perspective. Social Science and Medicine, 52(9), 1433-40.

Reventlow, S.D., Hvas, L. and Malterud, K. (2006). Making the invisible body visible: Bone scans, osteoporosis and women's bodily experiences. Social Science and Medicine, 62(11), 2720-31.

Richards, M. (1996). Families, kinship and genetics. In T. Marteau and M. Richards (Eds.), The troubled helix: Social and psychological implications of the new human genetics, pp. 249-73. Cambridge: Cambridge University Press.

Richards, M. (1997). It runs in the family: Lay knowledge about inheritance. In A. Clarke and E. Parsons (Eds.), Culture, kinship and genes: Towards crosscultural genetics, pp. 175-94. Basingstoke: Macmillan.

Riessman, C.K. (1990). Strategic uses of narrative in the presentation of self and illness. Social Science and Medicine, 30(11), 1195-200.

Ruston, A. and Clayton, J. (2002). Coronary heart disease: Women's assessment of risk - a qualitative study. Health Risk and Society, 4(2), 125-37.

Scott, S., Prior, L., Wood, F. and Gray, J. (2005). Repositioning the patient: The implications of being 'at risk'. Social Science and Medicine, 60(8), 1869-79.

Walter, F.M. and Emery, J. (2005). 'Coming down the line': Patients' understanding of their family history of common chronic disease. Annals of Family Medicine, 3(5), 405-14.

Walter, F.M., Emery, J., Braithwaite, D. and Marteau, T.M. (2004). Lay understanding of familial risk of common chronic diseases: A systematic review and synthesis of qualitative research. Annals of Family Medicine, 2(6), 583-94.

\section{Author biographies}

ANTJE LINDENMEYER has an interdisciplinary background in gender studies, social studies and literary studies, especially autobiography studies. She holds a PhD in Women and Gender Studies from the Centre for the Study of Women and Gender at the University of Warwick. She is a research fellow in primary care and has worked in the areas of patient involvement/empowerment, the self-management of chronic conditions and coping with disfigurement and other appearance issues. Her main research interest is in autobiographical narratives of health and illness and their impact on health care encounters.

FRANCES GRIFFITHS trained in medicine at Cambridge and Kings College Hospital, London and completed her PhD at the Department of Sociology and Social Policy, University of Durham. Frances joined the University of Warwick as senior clinical lecturer in 1998 and is a GP in Coventry. In 2003 she was awarded a UK Department of Health National Primary Care Career Scientist Award to develop a research programme on Complexity and Health Care. The programme aims to develop 
innovative research for developing the evidence base of primary care, informed by ideas of complexity sciences, drawing on diverse levels of analysis including the political, social, cultural, family, individual and biological.

EILEen GReEN is a founding Director of the Centre for Social and Policy Research that was established at Teesside in 1997. She was previously a Reader in Sociology at Sheffield Hallam University. Research interests include action projects on social in/exclusion, especially gender issues; leisure and paid employment; ethnicity, and information and communication technologies. Current projects include the final phase of three linked European Social Fund projects exploring the impact of social exclusion on women's labour market participation and co-researching on a Social Sciences and Humanities Research Council, Canada (SSHRC) funded project, Action For Health, with colleagues at Simon Fraser University, Vancouver.

DIANE THOMPSON is a Senior Research Fellow in the University of Hertfordshire's Centre for Research in Primary and Community Care (CRIPACC) with responsibilities for medicines management and public involvement in NHS research. Her interests lie in NHS primary care research; qualitative health research methods including narrative analysis and participatory research; feminist theory and sociology of the body, and critical social policy.

MARIA TSOUROUFLI's interests lie in gender studies and medical education. She is currently leading on a programme of qualitative research in postgraduate medical education. Her work is embedded in a post-structuralist feminist paradigm and informed by adult educational theory, medical sociology and the sociology of professions. It aims to bridge the gap between social sciences and medical education and to explore the impact of organizational management, culture and change on professionalism, medical training, patient care and inter-professional relations in medicine. 